\title{
ENTEROBACTERIAL CHELATORS OF IRON: THEIR OCCURRENCE, DETECTION, AND RELATION TO PATHOGENICITY
}

\author{
A. A. Miles AND P. L. KhimiI \\ Department of Clinical Investigation, Clinical Research Centre, Watford Road, \\ Harrow HAl 3UJ, Middlesex
}

Plates XLIII and XLIV

ENTEROBACTERIA synthesise a number of organic iron-chelating substances which are apparently necessary for their uptake of environmental iron. These chelators include phenolic acids such as 2,3-dihydroxybenzoic acid and the catechol 2,3-dihydroxybenzoylserine and its cyclic trimer, enterochelin, which is the most effective in the transport of iron to the bacterial cells (Pollack, Ames and Neilands, 1970). The compound 2,3-dihydroxybenzoylserine has been identified in Escherichia coli (Brot and Goodwin, 1968) and Aerobacter aerogenes (O'Brien, Cox and Gibson, 1969); and enterochelin in Salmonella typhimurium (Pollack and Neilands, 1970). These compounds are of interest in any consideration of microbial pathogenicity, since the growth of pathogenic strains in vivo depends in part on their capacity to obtain the iron firmly held by body substances like plasma transferrin-a major potential source of the iron that they need (see Bullen, Rogers and Lewin, 1971). Recently Rogers (1973) investigated two strains of $E$. coli, one virulent and the other relatively avirulent for the mouse. In chemically defined media containing some iron, the first strain produced substantial amounts of iron chelators, the second little; though both strains produced chelators well in media that contained virtually no iron. The virulence of the second strain was significantly increased when it was injected together with a preparation of $E$. coli iron chelator. These results indicate that adequate production of iron chelators in vivo may be necessary for the virulence of certain microbes.

It is generally assumed that the synthesis of iron-chelating catechols and their precursors is common to a number of enterobacterial species. The isolation of iron chelators from culture fluids and the proof of their biological activity-for example, by the promotion of the uptake of ${ }^{59} \mathrm{Fe}$ by bacteria in culture (Wang and Newton, 1969), the growth stimulation of species or strains deficient in the synthesis of iron chelators (Reich and Hanks, 1964; Pollack and Neilands, 1970), or the reversal of the bacteristatic action of horse serum on E. coli serotype O111 (Rogers, 1973) - are however too time-consuming for surveys of a large number of bacterial strains.

Received 29 Jan. 1975; accepted 25 Feb. 1975.

J. MED. MICROBIOL.-VOL. 8 (1975) 
The following is an account of a simple in-vitro test for iron chelators (here conveniently referred to as "chelators") by which it is possible to estimate: (1) the generality of chelator production within a species or genus; (2) the extent to which chelators from a given species or genus can promote the utilisation of bound iron by other species or genera; and (3) the relation, in pathogenic species, between virulence and the production of chelators.

\section{MATERIALS AND METHODS}

Ethylene diamine-di-orthohydroxyphenyl acetic acid (EDDA). Commercial EDDA (K. and K. Laboratories) was freed from contaminating iron by the method of Rogers (1973). Concentrated master solutions were made by dissolving the EDDA in $10 \mathrm{~N} \mathrm{NaOH}$ and bringing the $p \mathrm{H}$ to $7 \cdot 0$ by $10 \mathrm{~N} \mathrm{HCl}$.

Desferrioxamine $B$ was used in the form of desferrioxamine mesylate (Desferal) supplied by the Ciba Laboratories, Horsham.

Trace elements. A solution containing (per litre) $0.18 \mathrm{mg}$ of $\mathrm{Zn}$ (as $\left.\mathrm{ZnSO}_{4}\right), 0.40 \mathrm{mg}$ of $\mathrm{Cu}$ (as $\left.\mathrm{CuSO}_{4}\right), 0 \cdot 20 \mathrm{mg}$ of $\mathrm{Mn}$ (as $\mathrm{MnSO}_{4} .4 \mathrm{H}_{2} \mathrm{O}$ ), $0 \cdot 10 \mathrm{mg}$ of $\mathrm{Mo}$ as $\left(\mathrm{NH}_{4}\right)_{2} \mathrm{MoO}_{4}$ and $0 \cdot 10$ mg of $\mathrm{B}\left(\right.$ as $\left.\mathrm{H}_{3} \mathrm{BO}_{3}\right)$ was used to test reversal of the EDDA inhibition by trace elements other than Fe. This solution is 100 times more concentrated than that used to supplement media by Donald, Passey and Swaby (1952). It contained $<0.05 \mu \mathrm{g}$ of contaminating iron per ml.

Bacteria. The following strains were tested for chelator production:

Aeromonas spp.: Aerom. hydrophila ATCC nos. 7812, 7960, 7965, 9071; and ER75 and M90 (Miles and Miles, 1951).

Escherichia spp. All were E. coli, namely laboratory strains nos. K12 and 88; nos. 28B2 and 438, respectively properdin-sensitive and properdin-resistant strains from Professor A. C. Wardlaw; no. E2879 from the human gut and its R mutant no. E2880; and nos. E28 and E65, non-enteropathogenic and enteropathogenic strains respectively from the Central Public Health Laboratory, Colindale.

Klebsiella spp.: these included nos. A3sl and A4 (Dr I. W. Sutherland, College of Agriculture, Edinburgh); seven strains from various human infections collected by the Dysentery Reference Laboratory, Colindale-namely nos. 60/64, 72/64, 74/65,131/64,132/64, 225/69,701/66; and one strain of K. pneumoniae no. 49404 (Luton Public Health Laboratory).

Proteus spp.: nos. PR1, PR4, PR23 and PR30 are strains from human infections (Miles, 1951); and no. 254 and strain "Graves" are respectively properdin-sensitive and properdin-resistant strains from Professor A. C. Wardlaw.

Pseudomonas spp.: Ps. aeruginosa, nos. Ps116 and "Scudder" are laboratory strains; nos. $2171,5515,5525,5576,5641$ are strains from human infections (Central Public Health Laboratory, Colindale).

Salmonella and Shigella spp.: laboratory strains of Salm. dublin and Sh. sonnei were included; 12 strains of salmonellae (SF series) and 12 of shigellae (F series) as listed in table IV were from the Max-Planck-Institut für Immunbiologie, Freiburg.

Media. For klebsiellae and pseudomonads, the chemically defined mineral-salt medium of Davis and Mingioli (1950) in Oxoid Agar was used with sodium citrate $0.2 \%(\mathrm{w} / \mathrm{v})$ as the carbon source and enriched with peptone $0.02 \%(\mathrm{w} / \mathrm{v})$ (DMSCP medium). The iron content of this medium was about $0.25 \mu \mathrm{g}$ per $\mathrm{ml}$, of which the Oxoid Agar itself contributed about one-half. For the rest of the enterobacteria tested, DMSCP medium was enriched with glucose $0.2 \%(\mathrm{w} / \mathrm{v})(\mathrm{DMSCPG})$ and, for the more exacting aeromonads and shigellae, the peptone was increased to $0.1 \%(\mathrm{w} / \mathrm{v})$.

Viable counts were performed by the surface method of Miles, Misra and Irwin (1938); three or four plates were used for each dilution series. 
Assay of iron. The iron content of media was measured by the diphenyl phenanthroline method of Smith, McCurdy and Diehl (1952).

Preparation of microbial iron chelators. Chelators in substantial quantities were obtained by extraction of liquid cultures as described by Rogers (1973). A modification of this method was used to obtain smaller amounts for tests on indicator plates. A 10-ml overnight culture in DMSCPG medium was acidified to $p \mathrm{H} \mathrm{2.0}$ with $6 \mathrm{~N} \mathrm{HCl}$ and shaken with an equal volume of ethyl acetate. The ethyl acetate was separated, washed with an equal volume of $0.1 \mathrm{~N} \mathrm{HCl}$, separated again and any water present removed by treatment with $\mathrm{Na}_{2} \mathrm{SO}_{4}$. The extract was dried in vacuo and the residue containing the catechols, including the iron chelators, was taken up in $1.0 \mathrm{ml}$ of physiological saline.

Indicator plates for the detection of microbial iron chelators. Pour-plates of 9-cm diameter were made with $15-\mathrm{ml}$ volumes of medium containing EDDA and about $10^{4}$ viable indicator organisms per ml. The EDDA content ranged between 5 and $450 \mu \mathrm{g}$ per $\mathrm{ml}$ according to the medium and indicator organism. Concentrated EDDA solution was added to molten agar medium at $50^{\circ} \mathrm{C}$; the mixture was stored at $4^{\circ} \mathrm{C}$ for $1-3$ days and re-melted at $100^{\circ} \mathrm{C}$ for making the pour plates. The storage at $4^{\circ} \mathrm{C}$ is required to allow for a slow further binding of the $\mathrm{Fe}$ of the medium which is not apparent in pour-plates made immediately after addition of the EDDA at $50^{\circ} \mathrm{C}$. Holding the EDDA in the agar media either at $100^{\circ} \mathrm{C}$ for $1-2 \mathrm{~h}$ or at $120^{\circ} \mathrm{C}$ in the autoclave for $15 \mathrm{~min}$. immediately before pouring could not be substituted for the slow binding at $4^{\circ} \mathrm{C}$.

Bacteria were tested for chelator production by making spot inocula of $10^{6}-10^{7}$ colonyforming units (c.f.u.) in about $0.01 \mathrm{ml}$, from overnight cultures in Todd-Hewitt broth, on to the indicator plates which were examined after $18-20 \mathrm{~h}$ at $37^{\circ} \mathrm{C}$. The iron content of this volume of broth was insufficient to reverse the EDDA inhibition.

Bioassay of solutions containing iron chelators or iron. Graded concentrations of iron chelators or of iron-containing substances were applied to EDDA indicator plates either in 9-mm cups cut in the agar, or in " fish-spine" electrical insulating beads (Lightbown and Sulitzeanu, 1957) holding $27 \mu \mathrm{l}$ of liquid. With both classes of substance, a plot of the width of the zones of exhibition of microbial growth around the cups, or the diameters of zones around the beads, against the $\log _{10}$ concentration of EDDA was approximately linear, with slopes of about $5 \mathrm{~mm}$ for iron chelators and about $9 \mathrm{~mm}$ for solutions of iron salts.

Parallel lines, with a slope equal to the mean slope for a given assay, were fitted by eye to the linear responses, and relative potencies were estimated from the $\log _{10}$ concentrations producing an arbitrarily selected zone diameter.

Assay of the EDDA-sensitivity of bacteria. Plates of the agar medium appropriate for the group of organisms tested were seeded by flooding briefly with a suspension containing about $10^{5}$ viable bacteria per $\mathrm{ml}$; heavier seedings produce an unduly thick lawn of growth which is insensitive to the EDDA. When the plates were dry, solutions containing five concentrations of EDDA-0.0016, 0.08, 0.4, 2.0 and $10 \mathrm{mg}$ per $\mathrm{ml}$-were applied in fish-spine beads. Plots of the diameters or widths of either total or partial inhibition zones appearing after $18 \mathrm{~h}$ at $37^{\circ} \mathrm{C}$ were roughly linear with respect to $\log _{10}$ concentration of the EDDA. Parallel lines, with a slope equal to the mean slope for a given set of assays, were fitted by eye to the linear responses, and the relative sensitivities were estimated from the $\log _{10}$ concentrations producing an arbitrarily selected diameter of inhibition zone.

\section{RESULTS}

The in-vitro detection of microbial iron chelators

\section{Inhibition of growth by EDDA}

Our method of detecting iron chelators is based on an inoculum-dependent feature of the inhibition of bacterial growth on solid media by the synthetic iron chelator ethylene diamine-di-orthohydroxyphenyl acetic acid (EDDA). 
This is also described as $\mathbf{N}, \mathbf{N}^{\prime}$-ethylene bis 2-(orthohydroxyphenyl) glycine by L'Eplattenier, Murase and Martell (1967), who assign to the compound an association constant with ferric iron of $10^{33.9}$. Since the association constant of the next most avidly held trace metal $\mathrm{Cu}^{++}$is $10^{23 \cdot 9}$, EDDA clearly has a high specificity for iron.

When surface-viable counts of an organism are made on plates containing graded concentrations of EDDA, the growth of low-density seedings of up to 2000 c.f.u. per $\mathrm{cm}^{2}$ is progressively inhibited, as evidenced first by a decrease in colony size, then a total inhibition of growth; on the other hand, high-density seedings, especially those of $>10^{4}$ c.f.u. per $\mathrm{cm}^{2}$, sufficient to produce confluent or semiconfluent growth, grow well, though sometimes to a lesser extent in the presence of the higher concentrations of EDDA (table I). The same relation holds for high- and low-density seedings in the depth of an agar medium. It follows that a pour-plate with a low-density seeding of a bacterium in a minimal growth-inhibiting concentration of EDDA can serve as an indicator of chelators diffusing from a surface colony grown from a dense inoculum. After overnight incubation, colonies that produce chelators are surrounded by a zone of exhibition of the indicator colonies newly appearing in the depth of a clear medium. Cultures of any bacterium-including the indicator strain itself (fig. 1) - of which dense inocula will grow on the medium and at the EDDA concentration used, may be so tested. Partially inhibited indicator organisms may also be used; here the exhibition zones are composed of large colonies against a background of small colonies.

TABLE I

Surface-viable counts of Klebsiella strain $72 / 64$ on EDDA-containing agar media

\begin{tabular}{|c|c|c|c|c|c|c|c|c|c|c|}
\hline \multirow{3}{*}{$\begin{array}{c}\text { Culture } \\
\text { dilution } \\
1 \text { in }\end{array}$} & \multicolumn{10}{|c|}{$\begin{array}{l}\text { Mean count* on the stated medium with EDDA at the } \\
\text { stated concentration }(\mu \mathrm{g} \text { per ml) }\end{array}$} \\
\hline & \multicolumn{4}{|c|}{ DMSCPG agar } & \multicolumn{6}{|c|}{ Nutrient agar } \\
\hline & 0 & 20 & 100 & 500 & 0 & 20 & 100 & 200 & 300 & 500 \\
\hline $\begin{array}{l}10^{1} \\
10^{2} \\
10^{3} \\
10^{4} \\
10^{5} \\
10^{6} \\
10^{7}\end{array}$ & $\begin{array}{c}\mathrm{C} \\
\mathrm{C} \\
\mathrm{C} \\
\mathrm{sc} \\
66 \\
8 \\
0\end{array}$ & $\begin{array}{r}\mathrm{C} \\
\mathrm{C} \\
\mathrm{C} \\
\mathrm{sc} \\
70 \\
11 \\
0\end{array}$ & $\begin{array}{l}c \\
c \\
c \\
0 \\
0 \\
0 \\
0\end{array}$ & $\begin{array}{l}0 \\
0 \\
0 \\
0 \\
0 \\
0 \\
0\end{array}$ & $\begin{array}{l}C \\
C \\
C \\
\text { sc } \\
72 \\
9 \\
0.3\end{array}$ & $\begin{array}{l}\mathrm{C} \\
\mathrm{C} \\
\mathrm{C} \\
\mathrm{sC} \\
81 \\
9 \\
1 \cdot 0\end{array}$ & $\begin{array}{c}C \\
C \\
C \\
\text { sc } \\
80 \\
13 \\
1 \cdot 7\end{array}$ & $\begin{array}{l}\text { C } \\
\mathbf{C} \\
\mathbf{C} \\
\mathrm{sc} \\
8 \\
3 \cdot 3 \\
0\end{array}$ & $\begin{array}{l}\mathrm{C} \\
\mathrm{C} \\
\mathrm{C} \\
\mathrm{sc} \\
0 \\
0 \\
0\end{array}$ & $\begin{array}{l}C \\
C \\
C \\
\text { sc } \\
0 \\
0 \\
0\end{array}$ \\
\hline $10^{7}$ & \multicolumn{10}{|c|}{$\begin{array}{c}\text { Mean colony size (mm) under the conditions stated } \\
\text { above }\end{array}$} \\
\hline $10^{6}$ & $1 \cdot$ & $\begin{array}{l}0 \cdot \\
0\end{array}$ & $5 \cdots$ & $\ldots$ & $2 \cdot 6$ & $2 \cdot 5$ & $1 \cdot 6$ & 0.8 & $\cdots$ & $\cdots$ \\
\hline
\end{tabular}

\footnotetext{
* The mean number of colonies per $0.01-\mathrm{ml}$ drop is derived from results with three drops; sc, c, $\mathrm{C}=$ semiconfluent, confluent and abundant confluent growth.
} 


\section{The iron specificity of growth inhibition by EDDA}

In view of the high association constant of the iron-EDDA complex, it is a reasonable assumption that the growth inhibition is due to a deficiency of readily available iron in the medium, and that the exhibition of growth of the indicator organism is attributable to the release of iron from the EDDA by diffusible chelators from the test colony. The validity of this assumption is strengthened by the following facts.

Zones of exhibition formed around cups in the agar medium containing iron-chelating catechols from Klebsiella spp. (fig. 2) and the iron chelator desferrioxamine B derived from Streptomyces (Bickel et al., 1960). Citrate, a feeble iron chelator, and 2,3-dihydroxybenzoate, a precursor of 2,3-dihydroxybenzoylserine, were inactive.

Iron supplied in excess of what could be held by the EDDA present also induced growth of the indicator organisms. Exhibition zones formed around cups containing low concentrations of ferric ammonium sulphate, ferrous gluconate or ferrous sulphate. Since the width of the zone was linearly related to the $\log _{10}$ concentration of iron, the potency was measurable in terms of a dose-response line with a slope of about $9 \mathrm{~mm}$. All three salts were approximately equipotent at equal iron content. Even metallic iron, in the form of a brightly polished strip on the surface of the agar, yielded enough soluble iron during incubation to reverse the EDDA inhibition (fig. 3). Guinea-pig haemoglobin, and commercial haematin and ferritin, were also active.

The mixture of the other trace elements that influence microbial growth $-\mathrm{B}$, $\mathrm{Cu}, \mathrm{Mn}, \mathrm{Mo}$ and $\mathrm{Zn}-$ at 50 times the concentrations required in minimal media was without effect in overcoming the inhibition by EDDA, as were high concentrations of $\mathrm{Ca}$ and $\mathrm{Mg}$ salts.

\section{The indicator system}

The indicator organism in the EDDA plates may be either totally or partly suppressed. With total suppression the exhibition zones are clear and small degrees of exhibition are readily detected. With partial suppression the zones are less clear, but there is the added advantage of being able to recognise the secretion by the test colony of substances that inhibit the growth of the indicator organism. These substances are undetectable with a totally suppressed indicator and this could mask the effect of simultaneously produced chelators which must then be sought in extracts of liquid cultures of the organisms.

Indicator strains. Indicator strains were selected by tests of the relative EDDA sensitivity of each species or genus of bacteria examined. Fig. 4 exemplifies such a test, with seven strains of Klebsiella. The slopes of the responses are approximately parallel. In this test the mean slope was 6.6 , and the estimated relative sensitivities of six of the strains lay between 0.7 and 1.5 , the value of 1.0 being assigned to strain $60 / 64$; no. $701 / 66$ was 10.4 times more sensitive than no. $60 / 64$. In another test, not shown in fig. 4 , strain $72 / 64$ was 19.8 times more sensitive than strain $60 / 64$, and was accordingly used as the

J. MED. MICROBJOL.-VOL. 8 (1975) 
klebsiella indicator. The minimum totally suppressing concentration of EDDA for this strain in DMSCP indicator plates was $50 \mu \mathrm{g}$ per $\mathrm{ml}$.

Similar results were obtained with collections of aeromonads, escherichiae, Proteus spp., pseudomonads, salmonellae and shigellae and, where possible, outstandingly sensitive strains were chosen as indicators. The estimates of susceptibility and the slope of the dose-response lines varied with the species tested, the density of the seeding and the medium, but the order of susceptibility

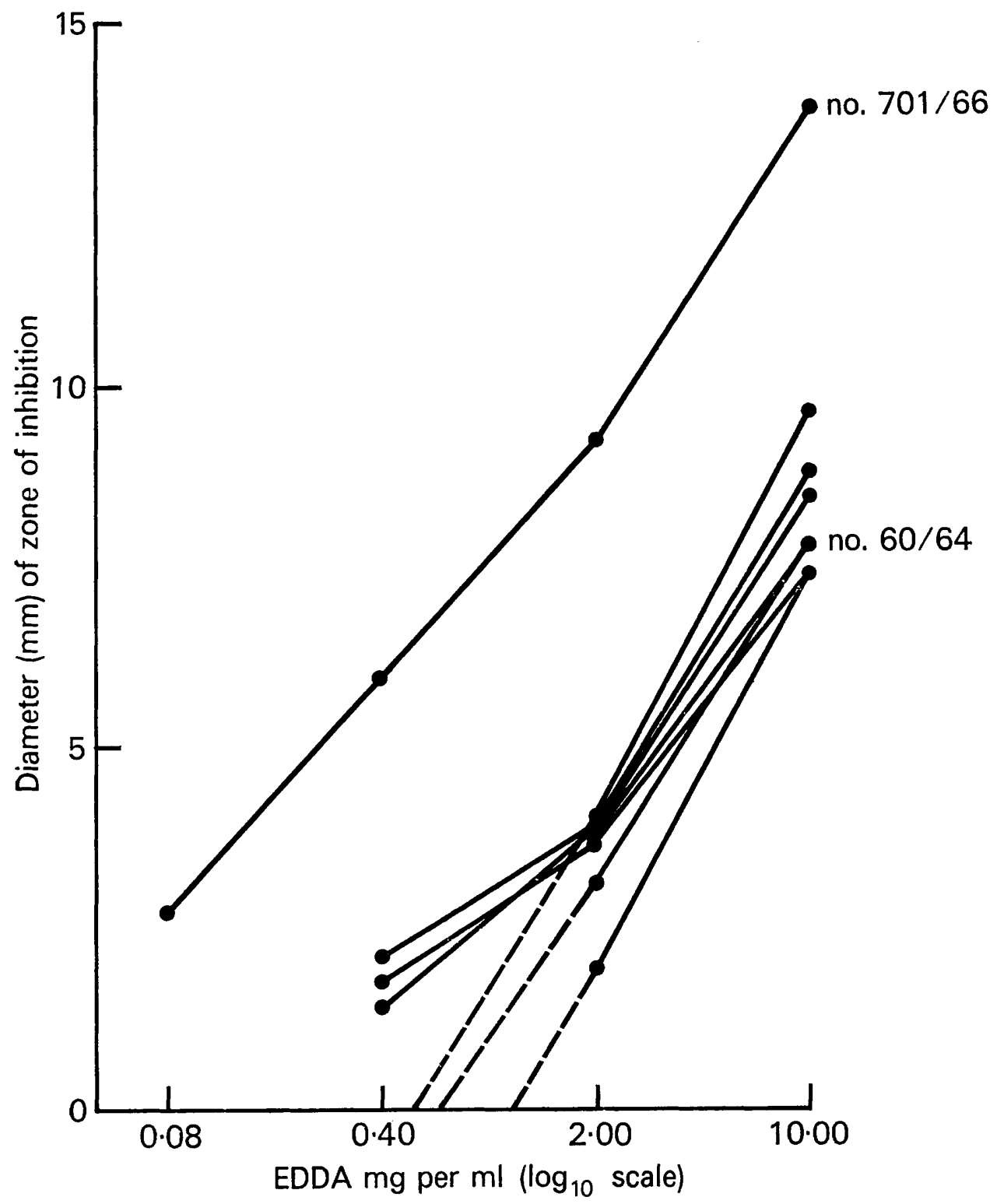

FIG. 4.-Determination of the EDDA sensitivity of seven strains of Klebsiella. 
in a given group did not change significantly with repeated tests. Proteus spp. were all highly susceptible to EDDA, and a proteus indicator proved to be very useful for general surveys.

With groups of bacteria from which no particularly susceptible strain emerged that could be used as a totally suppressed indicator, a strain whose colony size was substantially diminished by the EDDA was used to make partly suppressed indicator plates.

Concentration of EDDA. The appropriate concentration of EDDA for a given medium was determined by trial. Table II shows the result of one such test with a strain of Sh. sonnei as indicator in DMSCPG agar. EDDA at $450 \mu \mathrm{g}$ per $\mathrm{ml}$ is clearly the best for the detection of bacterial chelators, although even at this concentration the suppression of growth in the absence of chelators was incomplete. The lowest possible concentration was used for each system, since the indicator medium had sometimes to support the surface growth of highly EDDA-sensitive test strains.

Concentration of bacteria. The concentration of viable indicator organisms is critical (see Methods). It should not be higher than $10^{4}$ per $\mathrm{ml}$ because the inoculum is then too dense for the manifestation of inhibition by EDDA. Concentrations of $<10^{4}$ per $\mathrm{ml}$ may be used, but the edges of the exhibition zones are less well defined. The spot inoculum of the test organism should be as dense as can be readily obtained in overnight liquid culture.

Quantitation of chelator secretion. Preparations of iron-chelating catechols in fish-spine beads produce exhibition zones with diameters proportional to the $\log _{10}$ concentration of the chelator, with a slope of about $6 \mathrm{~mm}$ (see Methods). The diffusion of chelators as they are synthesised and released by the growing colonies of test organisms is not strictly comparable with the diffusion of preformed chelators from reservoirs on the surface of the agar. The circumstances are nevertheless similar enough to justify the assumption that when two test colonies of equal density of growth produce zones of equal intensity and diameter, they are producing chelators in approximately equal amounts. On the other hand, when there is a difference of several millimetres between two zonal diameters round similarly dense colonies, a substantial difference in degree of chelator production may be assumed.

\section{The functional similarity of iron chelators among strains, species and genera of enterobacteria}

Representatives of seven enterobacterial genera listed in the Materials and Methods section were tested.

The indicator strains mainly used, and the inhibiting concentration of EDDA ( $\mathrm{E}$ in $\mu \mathrm{g}$ per $\mathrm{ml}$ ) for these strains were as follows: Aerom. hydrophila no. 7812 (E400), E. coli serotype O111 (E50), Klebsiella no. 72/64 (E50), Proteus no. 254 (E10), Pseudomonas no. 116 (E200), Salm. minnesota no. SF1111 (E450), Salm. typhimurium no. SF1481 (E50), Sh. sonnei (E450), Sh. dysenteriae nos. F3161 (E10) and F3129 (E5).

As a rule, 12 sites on each plate were used, either seeded with test colonies 
(fig. 5) or treated with $27 \mu 1$ of test solution in fish-spine beads. The diameters of the exhibition zones, which ranged from 3 to $30 \mathrm{~mm}$ or more, was recorded after $18 \mathrm{~h}$ at $37^{\circ} \mathrm{C}$. Table II summarises the results of a typical test. With low concentrations of EDDA, the inhibition of the indicator was insufficient, and no zones were discernable. With medium concentrations, unstimulated indicator colonies were sufficiently small to be distinguished from stimulated colonies and for exhibition zones to be defined. With concentrations high enough partly to inhibit the growth of the test colony, exhibition zones were nevertheless prominent-owing presumably to an adaptive increase in chelator production as a response to the paucity of free iron in the medium (cf. Neilands, 1966).

The optimum EDDA concentration for demonstration of the activity of Proteus strain no. 254 and of desferrioxamine B was not that for the other microbial chelators; moreover, the reversal of inhibition by klebsiella catechols was dubious. These observations indicate the need for empirical adjustment of the conditions of the test according to circumstances, particularly when no chelators are detectable. Negative results of this kind were not accepted unless they were consistently so in repeated tests. Once a positive was obtained with a particular test-indicator pair of strains, it was recorded as such, without regard to any previous negative results.

TABLE II

Results of studies of the growth of test colonies and production of iron chelators on EDDADMSCPG plates with Shigella sonnei as indicator

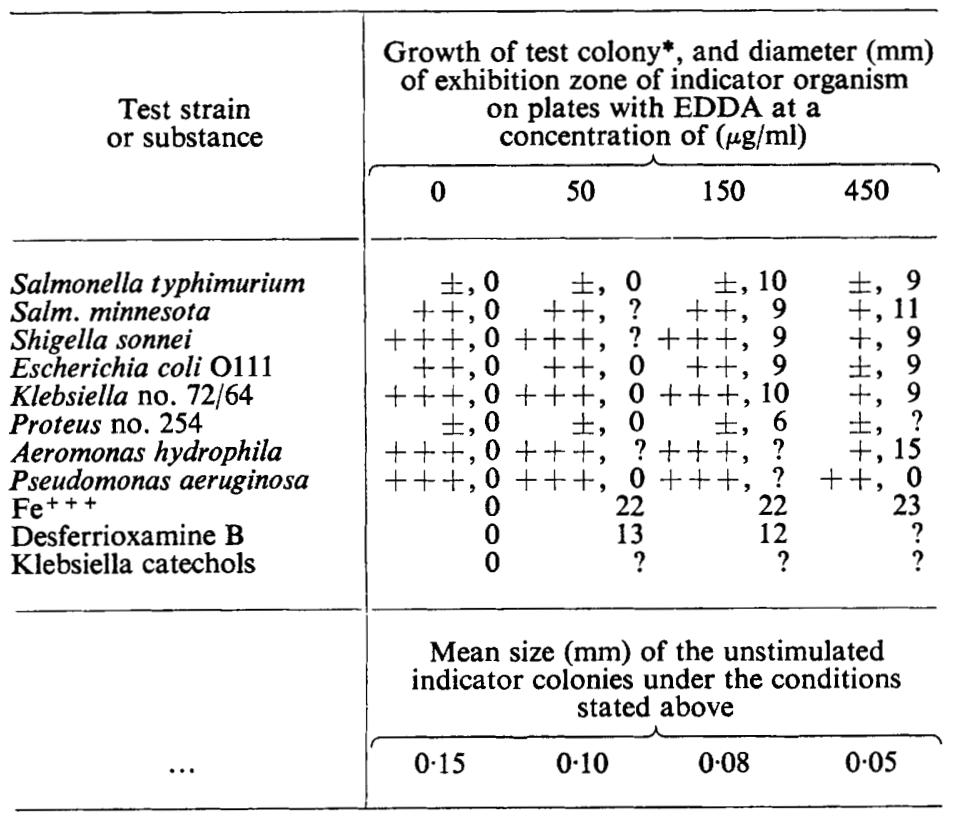

\footnotetext{
* \pm to $+++=$ thin transparent to heavy opaque confluent growth of test colony; $?=$ dubiously positive.
} 
The results are summarised in table III. To these must be added the results with test solutions; namely that the EDDA inhibition of all the indicator organisms used was reversed by desferrioxamine B, by a preparation of klebsiella catechols and by ferric ions; but not by the mixture of other trace elements in 50 times the minimal growth-stimulating concentration. In all but five instances, where some of the results are negative, the microbial chelators are functionally interchangeable within the species and, where more than one species of a genus was tested, within the genus. They are also interchangeable between genera (fig. 6). The secretion by the test colony of substances inhibiting the growth of the indicator organism accounts for two of four negative results with Aeromonas (table III, row 1) and six of eight negatives with Pseudomonas (row 5) in tests against Klebsiella. The consistently negative results with Pseudomonas on Escherichia and Proteus (row 5) are most probably due to the simultaneous excretion by the pseudomonads of bactericidal substances, which was evident on plates with partly suppressed indicator organisms; and those with Proteus on Klebsiella (row 4) to poor chelator production. In these cases, proof of intergeneric activity was made with liquid cultures or with extracts of catechols from liquid cultures. With poor producers like Proteus, it was sufficient to acidify an overnight culture in DMSCPG to $p \mathrm{H} 6.0$ and inactivate at $60^{\circ} \mathrm{C}$ for $30 \mathrm{~min}$. to obtain a positive result with cups in a klebsiella indicator plate. Extraction of pseudomonas cultures with ethyl acetate extracted the active chelators and evidently left behind the antibacterial material produced by the organisms, for pseudomonas catechols prepared as above reversed the EDDA-inhibition of E. coli and Proteus.

The functional interchangeability of iron chelators may therefore be regarded as complete within the $7 \times 7$-fold scheme set out in table III.

\section{Iron-chelator production and virulence}

Of two randomly selected strains of $E$. coli, nos. E28 and E65, one nonenteropathogenic and the other enteropathogenic, both were active producers

TABLE III

Production of iron chelators in vitro

\begin{tabular}{|c|c|c|c|c|c|c|c|}
\hline \multirow{2}{*}{$\begin{array}{l}\text { Genus of } \\
\text { test } \\
\text { (producer) } \\
\text { colony }\end{array}$} & \multicolumn{7}{|c|}{$\begin{array}{c}\text { Number of strains positive/number of strains tested } \\
\text { against the stated indicator* }\end{array}$} \\
\hline & Aerom. & $E$ & $K$ & Pr. & Ps. & Salm. & $S h$. \\
\hline $\begin{array}{l}\text { Aeromonas } \\
\text { Escherichia } \\
\text { Klebsiella } \\
\text { Proteus } \\
\text { Pseudomonas } \\
\text { Salmonella } \\
\text { Shigella }\end{array}$ & $\begin{array}{l}1 / 1 \\
1 / 1 \\
1 / 1 \\
1 / 1 \\
1 / 1 \\
3 / 3 \\
1 / 1\end{array}$ & $\begin{array}{l}3 / 6 \\
8 / 8 \\
1 / 1 \\
1 / 1 \\
0 / 5 \\
4 / 4 \\
3 / 5\end{array}$ & $\begin{array}{c}2 / 4 \\
4 / 4 \\
10 / 10 \\
0 / 6 \\
6 / 8 \\
12 / 12 \\
12 / 12\end{array}$ & $\begin{array}{l}3 / 3 \\
1 / 1 \\
1 / 1 \\
1 / 1 \\
0 / 4 \\
1 / 1 \\
1 / 1\end{array}$ & $\begin{array}{l}1 / 1 \\
1 / 1 \\
1 / 1 \\
1 / 1 \\
2 / 2 \\
1 / 1 \\
1 / 1\end{array}$ & $\begin{array}{c}1 / 1 \\
2 / 2 \\
1 / 1 \\
1 / 1 \\
1 / 1 \\
13 / 13 \\
13 / 13\end{array}$ & $\begin{array}{l}1 / 1 \\
1 / 1 \\
1 / 1 \\
1 / 1 \\
1 / 1 \\
13 / 13 \\
13 / 13\end{array}$ \\
\hline
\end{tabular}

* The abbreviations relate respectively to the genera listed in column 1. 
TABLE IV

Comparison of iron-chelator production by virulent-avirulent $(S-R)$ pairs of enterobacteria

\begin{tabular}{|c|c|c|c|c|c|c|c|}
\hline \multirow[t]{2}{*}{ Test (producer) organism } & \multicolumn{2}{|c|}{$\begin{array}{l}\text { Strain no. } \\
\text { and form* }\end{array}$} & \multicolumn{5}{|c|}{$\begin{array}{l}\text { Comparative result of chelator production } \\
\text { test with S-R pairs against indicator strains } \\
\text { of the stated genus } \dagger\end{array}$} \\
\hline & $\mathbf{S}$ & $\mathbf{R}$ & Salm. & Sh. & Pr. & $K$ & $E$. \\
\hline $\begin{array}{l}\text { Escherichia coli } \\
\text { Salmonella minnesota } \\
\text { Salm. paratyphi } \\
\text { Salm. typhimurium } \\
\text { Salm. typhimurium } \\
\text { Salm. typhimurium } \\
\text { Salm. virginia } \\
\text { Shigella dysenteriae, type } 1 \\
\text { Sh. dysenteriae, type } 2 \\
\text { Sh. dysenteriae, type } 3 \\
\text { Sh. dysenteriae, type } 4 \\
\text { Sh. boydii, type } 3 \\
\text { Sh. flexneri, type } 6\end{array}$ & $\begin{array}{r}\text { E2879 } \\
\text { SF1111 } \\
\text { SF1476 } \\
\text { SF1135 } \\
\text { SF1576 } \\
\text { SF1826 } \\
\text { SF1480 } \\
\text { F3127 } \\
\text { F3129 } \\
\text { F3130 } \\
\text { F3131 } \\
\text { F3141 } \\
\text { F3149 }\end{array}$ & $\begin{array}{r}\text { E2880 } \\
\text { SF1167 } \\
\text { SF1477 } \\
\text { SF1605 } \\
\text { SF1567 } \\
\text { SF1828 } \\
\text { SF1481 } \\
\text { F3128 } \\
\text { F3158 } \\
\text { F3160 } \\
\text { F3161 } \\
\text { F3157 } \\
\text { F3154 }\end{array}$ & $\begin{array}{l}\text { nt } \\
= \\
= \\
= \\
= \\
= \\
= \\
= \\
= \\
= \\
= \\
= \\
=\end{array}$ & 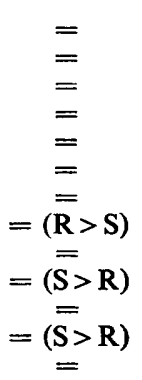 & $\begin{array}{c}\text { nt } \\
= \\
= \\
= \\
= \\
= \\
= \\
=(\mathbf{R}>S) \\
\text { nt } \\
\text { nt } \\
\text { nt } \\
\text { nt } \\
\text { nt }\end{array}$ & $\begin{array}{c}= \\
= \\
= \\
= \\
= \\
=(\mathbf{S}>\mathrm{R}) \\
= \\
= \\
\mathrm{R}>\mathrm{S} \\
= \\
\mathrm{S}>\mathrm{R} \\
= \\
=\end{array}$ & $\begin{array}{l}= \\
= \\
\text { nt } \\
\text { nt } \\
= \\
= \\
= \\
\text { nt } \\
\text { nt } \\
\text { nt } \\
= \\
\text { nt } \\
=\end{array}$ \\
\hline
\end{tabular}

* $\mathrm{S}=$ smooth; $\mathrm{R}=$ rough.

$\dagger$ Salm. = Salmonella $; \quad$ Sh. $=$ Shigella $; \quad P r .=$ Proteus $; \quad K .=$ Klebsiella $; \quad E .=$ Escherichia $\mathrm{nt}=$ not tested; =: equal production by $S$ and $\mathrm{R}$ forms; results given in brackets indicate occasional findings in replicate tests.

of chelators. Among ten randomly selected strains of Klebsiella spp., whose guinea-pig virulence extended over a 200 -fold range (to be published), there was no significant association with chelator production (fig. 7); some of the least virulent were the best producers.

The more cogent tests were made with 13 fully smooth (S) forms and their fully rough $(\mathrm{R})$ mutants. Indicator organisms of the homologous genus were used, but indicators of " alien " genera were also tested. These S-R pairs, of $E$. coli, salmonellae and shigellae, are listed in table IV. In all but a few tests, the zone of exhibition around each member of each pair was of almost identical diameter (figs. 5 and 8). The outstanding discrepancies were few, and usually on indicators of an alien genus. In these instances there was no systematic tendency for $\mathrm{S}$ forms to be more active than $\mathrm{R}$ forms, or vice versa.

\section{Other applications}

\section{Extension of surveys}

The above surveys were limited to enterobacteria, largely because these organisms grew readily on simple media. Provided that the right media, indicator organisms and EDDA concentration can be obtained, the method is applicable to studies of other groups of bacteria. For example, on nutrient agar media, three strains of Staphylococcus aureus were active on $E$. coli serotype O111 and Proteus no. 254, though the zones of exhibition were very indistinct, and representatives of all seven enterobacterial genera were active on a staphylococcus indicator. 


\section{Detection and assay of isolated microbial iron chelators}

Replicate tests with EDDA plates incorporating a totally suppressed indicator species are useful for the accurate biological assay of chelators (cf. Reich and Hanks, 1964).

A modified procedure has proved useful for analysing paper chromatograms of catechol material extracted from cultures. Completely volatile solvents are used to develop the chromatogram, which is then dried and cut through the middle along its entire length. One half is treated conventionally and the other is laid on appropriate indicator plates. The position of any iron chelators is indicated by the exhibition zones that appear along the edge of the strip.

\section{DisCussion}

Our results provide strong evidence that the diffusible substances released from test colonies of " producer" strains reverse the growth-inhibition of the "indicator" organisms because they are chelators with a sufficiently high avidity for iron to remove it from the EDDA-iron complexes present in the medium. The association constant of EDDA with ferric iron is as high as $10^{33 \cdot 9}$.

The nature of the chelators was not established, but in three generaKlebsiella, Proteus and Pseudomonas - the active material resembled the iron chelators already identified in some enterobacteria in that it appeared in the catechol fractions extractable from liquid cultures. Although we have demonstrated the functional interchangeability of the chelators, both qualitatively and to a substantial degree quantitatively, among the enterobacteria investigated, this is not evidence that they are all derivatives of phenolic acids like 2,3dihydroxybenzoylserine. The equal efficacy of the trihydroxamic acid derivative, desferrioxamine $\mathrm{B}$, and the iron-chelating catechols from klebsiellae confirms the experience of others that chelators of widely differing origin and structure may be utilised for iron transport by a given organism. For example, Bacillus subtilis, whose native iron chelator is 2,3-dihydroxybenzoylglycine (Ito and Neilands, 1958) is stimulated to take up iron by ferrichrome, a cyclic hexapeptide in which the iron is complexed to three hydroxamate groups (Peters and Warren, 1970); Pasteurella tularense secretes an iron chelator that can be substituted by ferrioxamine or ferrichrome (Halmann and Mager, 1967); and the chelator formed by Salm. typhimurium, 2,3-dihydroxybenzoylserine, can be substituted by ferrichrome (Pollack et al., 1970) or 2,3-dihydroxybenzoylglycine (Walsh and Warren, 1971).

It is evident that the interchangeability of iron chelators is a general feature of enterobacteria, though exceptions may be established with further surveys of this large family. The method we have described could be used for studies of other groups of organisms provided that due regard is paid to the sensitivities of the test and indicator organisms in whatever medium is used. It has many advantages over methods dependent on finding chelator-poor strains to serve as indicators; such as the Arthrobacter terragens procedure used for mycobactin 
assay (Reich and Hanks, 1964) or methods employing mutants of Salm. typhimurium (Pollack et al., 1970) and E. coli (Wang and Newton, 1969) whose iron uptake or growth is stimulated by enterochelins. It provides a simple, easily set up biological system for the semiquantitative detection of iron chelators from growing colonies, and for the accurate assay of chelators in solution.

Both Rogers (1973) with E. coli and Golden, Kochan and Spriggs (1974) with tubercle bacilli demonstrated that the avirulent and virulent forms of these two organisms were equally good producers of iron-chelators in certain circumstances in vitro. The point is of some importance: because bacteria presumably need iron for growth in vivo as well as in vitro, the capacity to produce iron chelators, though a necessary feature of a virulent bacterium, is not a determinant of virulence. These workers used randomly selected strains. However, if the virulent strains had proved to produce far more chelator than the avirulent, that difference might have been due to a metabolic peculiarity that had no direct connection with virulence. There would have been a greater likelihood of a significant association of the two properties if chelator production had been demonstrable in a virulent form and lost during its mutation to nonvirulence.

As to the relation of chelator production and virulence in the present study, there is no basis for supposing that chelator production per se distinguishes avirulent from virulent forms in a pathogenic species. With all the strains tested on indicator organisms of a like genus and often of other genera, both forms produced approximately the same amount of chelator in vitro. Whether that potential would be expressed equally well in vivo cannot be decided by in-vitro tests.

From both in-vitro and in-vivo tests, Rogers (1973) concluded that the mouse-avirulent $E$. coli serotype $\mathrm{O} 111$ and the mouse-virulent $E$. coli serotype O141 both produced catechol chelators in iron-poor environments, and both could thereby obtain iron from the iron-transferrin complex of plasma, but that other substances in the plasma inhibited the synthesis or secretion of chelators by the relatively avirulent $\mathrm{O} 111$ strain. Equal mycobactin production in vitro by avirulent and virulent tubercle bacilli was observed by Golden et al. (1974), who found however that surface-active agents removed mycobactin much more readily from avirulent strains; these workers suggested that the lipid-rich surface of virulent strains holds mycobactin better than the lipid-poor avirulent strains, thus enabling the virulent strains to grow better in vivo.

There are in-vitro parallels to this situation of equal production in one circumstance and not in another. Some of our shigella R-S pairs, equally productive with a shigella indicator, were grossly different on an "alien" indicator such as Klebsiella, one or the other member of the pair producing no chelators. If a difference of indicator strains can affect the metabolic powers of a bacterium in a relatively simple in-vitro system, the complex circumstances of an in-vivo infection may well do so.

Rogers (1973) calls the capacity of his virulent $E$. coli to synthesise and excrete iron chelators in vivo a "virulence factor". The commonly accepted 

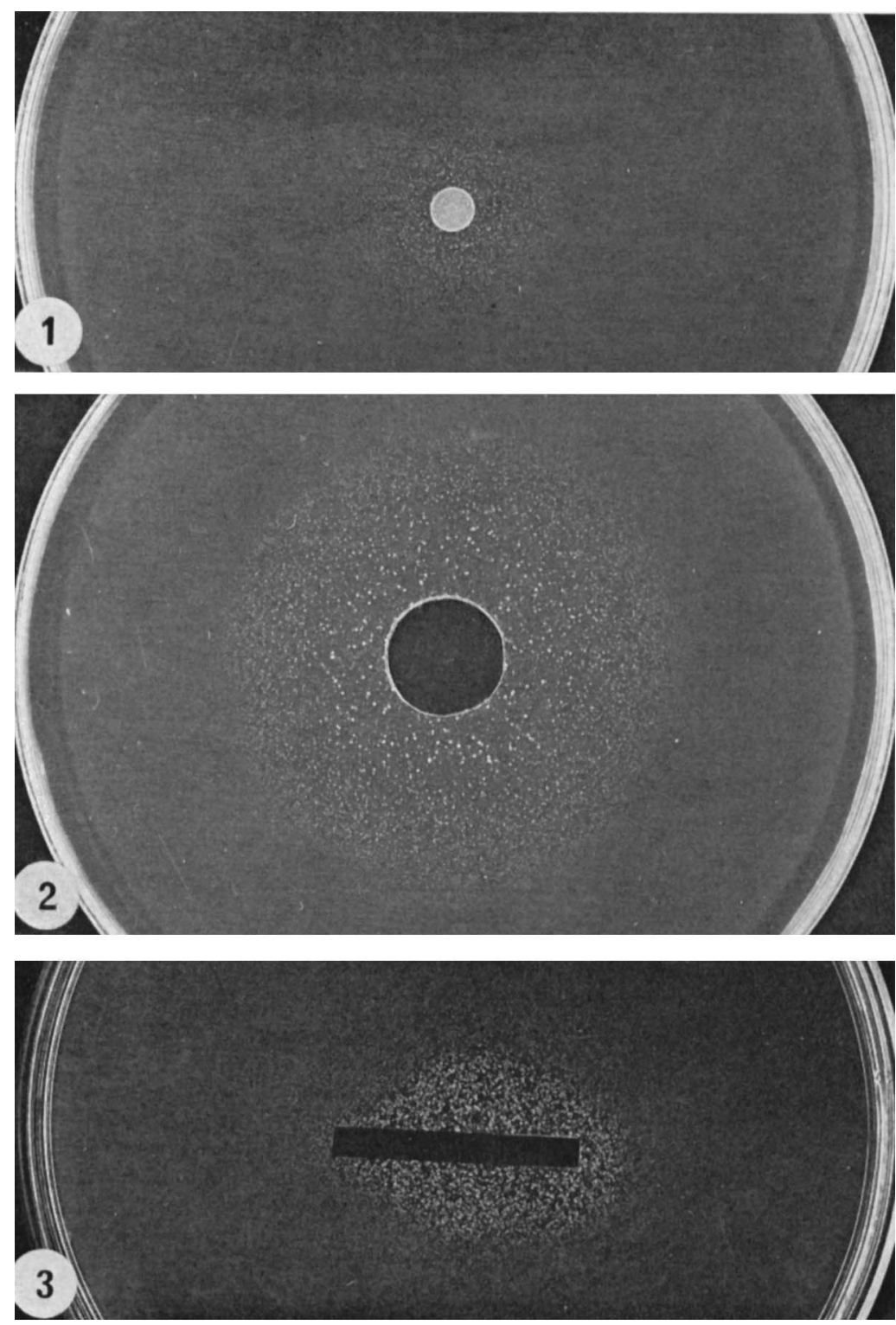

Fig. 1.-Surface colony of a klebsiella strain, no. 72/64, inducing an exhibition zone of growth of a low-density seeding of the same organism in the depth of an EDDA-agar medium.

FIG. 2.-Reversal of the EDDA-inhibition of a klebsiella by a solution of the iron-chelator desferrioxamine $\mathrm{B}$.

FIG. 3.-Reversal of the EDDA-inhibition of a klebsiella by a strip of metallic iron. 


\section{ENTEROBACTERIAL IRON CHELATORS}

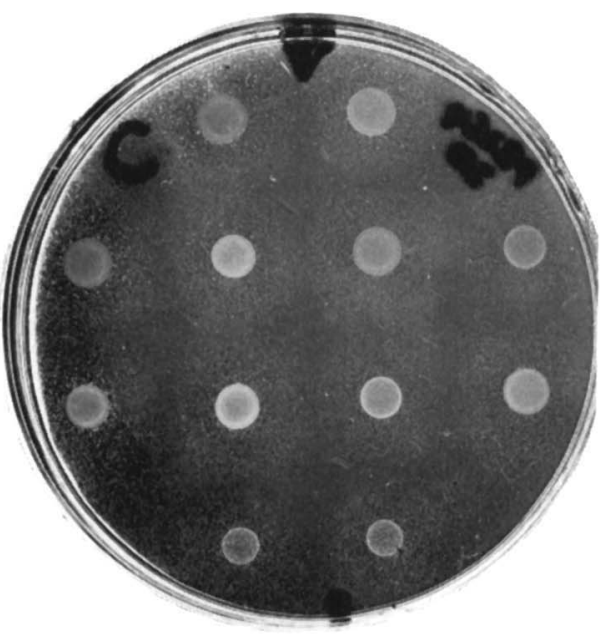

Fig. 5.-Equality of iron-chelator production by colonies of six S-R pairs of salmonella strains. The $\mathbf{S}$ and $\mathbf{R}$ strains alternate along the rows, from left to right. The indicator organism was Proteus strain 254.

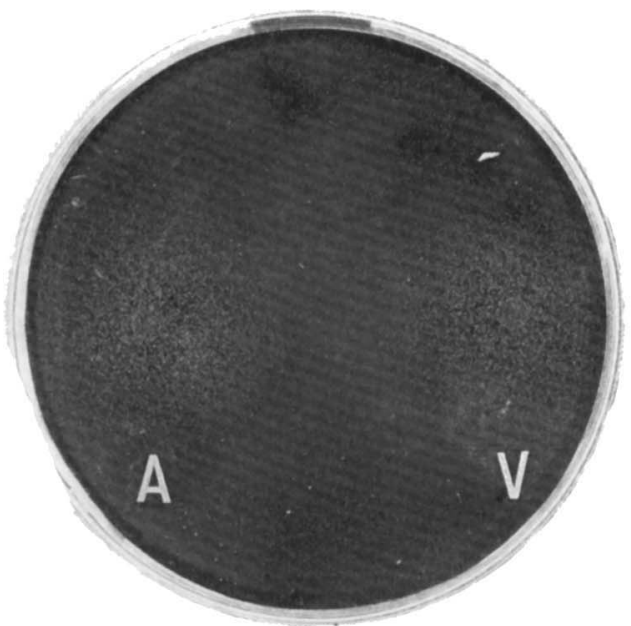

FIG. 7.-Equality of iron-chelator production by an avirulent klebsiella strain (A) and a strain 200 times more virulent (V). The indicator organism was Proteus strain no. 254.

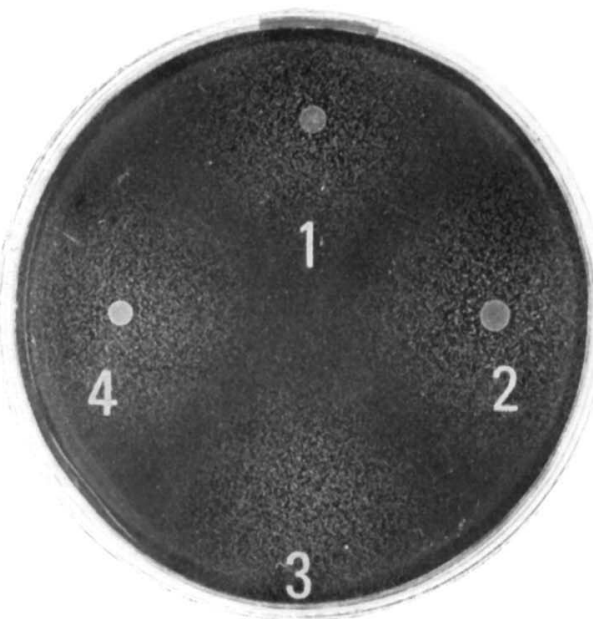

Fig. 6.-Iron-chelator production by strains of (1) E. coli, (2) Klebsiella sp. (3) Sh. boydii, and (4) Salm. minnesota. The indicator organism was Proteus strain 254.

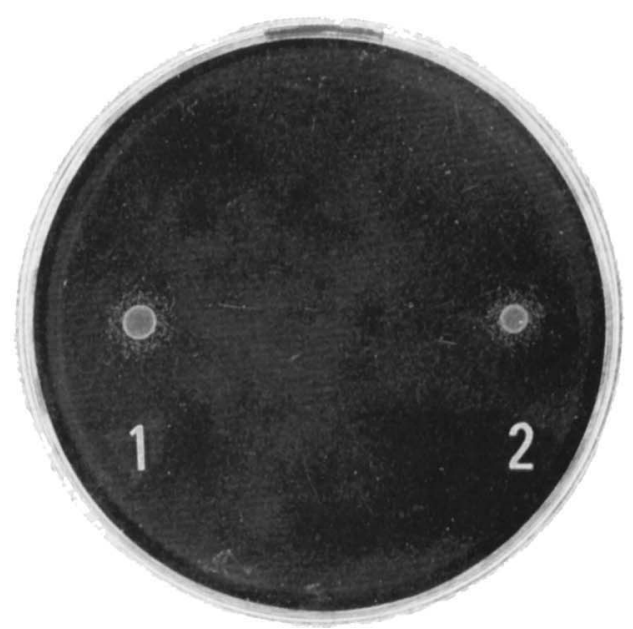

Fig. 8.-Equality of iron-chelator production by an $\mathrm{S}$ form of $S h$. dysenteriae type 3 (1) and its fully $\mathrm{R}$ mutant (2). The indicator organism was Sh. dysenteriae type 4. 
notion of virulence factors is of substances that are either directly toxic to the host, e.g., diphtheria toxin, or antagonise the antibacterial mechanisms of the host, e.g., the capsule of the pneumococcus; such a factor is possessed by virulent but not by avirulent strains. In this sense the iron-binding pesticin $I$ is a virulence factor of Yersinia pestis, since strains of $Y$. pestis that do not synthesise it are less virulent (Brubaker, Beesley and Surgalla, 1965).

However, the capacity to express in vivo a metabolic property that is common to both virulent and avirulent forms cannot usefully be termed a virulence factor, because the capacity to display in vivo any one of the hundreds of metabolic activities common to both forms can by the same reasoning be classified as a virulence factor; and the term becomes so all-embracing as to obscure the valuable distinction implied in confining it to those activities that are peculiar to virulent forms.

Clearly a virulent form must have factors, peculiar to itself, which enable it to display all the common metabolic activities in vivo; but those factors are not the common metabolic activities themselves. All that can justifiably be said about enterobacterial iron chelators in this respect is that the capacity to produce chelators is necessary for virulence, but does not determine it.

\section{SUMMARY}

In or on agar media, low-density seedings of enterobacteria fail to grow in the presence of certain concentrations of ethylene diamine-di-orthohydroxyphenyl acetic acid (EDDA); on the other hand, high-density seedings not only grow but secrete iron chelators which release the iron bound by the EDDA in the medium and stimulate the growth of low-density seedings.

Plates of media containing EDDA with low-density seedings of indicator organisms were used to survey iron-chelator production in seven enterobacterial genera, including a number of virulent smooth (S) forms from which rough (R) mutants had been obtained. An examination of over 80 strains of Aeromonas, Escherichia, Klebsiella, Proteus, Pseudomonas, Salmonella and Shigella species indicated that the iron chelators from bacteria in all these genera were functionally interchangeable.

Chelator production was equally good with randomly selected avirulent and virulent strains of Klebsiella spp. and E. coli; and with the S forms and their avirulent $R$ mutants in one pair of escherichiae, six pairs of salmonellae (4 species) and six pairs of shigellae (3 species). As determinable in vitro, the capacity to synthesise iron chelators is clearly no index of the capacity of a strain to proliferate in vivo.

We are indebted to Dr I. W. Sutherland and the late Dr Patricia Carpenter for klebsiella strains; to Doctors M. T. Parker and B. Rowe of the Central Public Health Laboratory, Colindale, for Pseudomonas and Escherichia strains; to Dr Günter Schmidt of the MaxPlanck-Institut für Immunbiologie, Freiburg, Germany, for the S-R pairs of Shigella and Salmonella species; to Dr Henry Rogers of the National Institute for Medical Research, Mill Hill, for iron-free EDDA; and to Dr D. M. Burley of the Ciba Laboratories, Horsham, for a gift of Desferal. 


\section{REFERENCES}

Bickel, H., Hall, G. E., Keller-Schierlein, W., Prelog, V., Vischer, E. and Wettstein, A. 1960. Metabolic products of Actinomycetes; 27th communication on the constitution of ferrioxamine B. Helv. chim. acta, 43, 2129.

Brot, N. AND Goodwin, J. 1968. Regulation of 2,3-dihydroxybenzoylserine synthetase by iron. J. biol. chem., 243, 510 .

Brubaker, R. R., Beesley, E. D. ANd Surgalla, M. J. 1965. Pasteurella pestis; role of pesticin I and iron in experimental plague. Science, N.Y., 149, 422.

Bullen, J. J., Rogers, H. J. AND LewiN, J. E. 1971. The bacteriostatic effect of serum on Pasteurella septica and its abolition by iron compounds. Immunology, 20, 391.

Davis, B. D. AND MingIoli, E. S. 1950. Mutants of Escherichia coli requiring methionine or vitamin B12. J. Bact., 60, 17.

Donald, C., Passey, B. I. AND Swaby, R. J. 1952. A comparison of methods for removing trace metals from microbiological media. J. gen. Microbiol., 7, 211.

Golden, C. A., Kochan, I. AND SpRIGgs, D. R. 1974. Role of mycobactin in the growth and virulence of tubercle bacilli. Infect. Immun., 9, 34.

Halmann, M. AND Mager, J. 1967. An endogenously produced substance essential for growth initiation of Pasteurella tularensis. J. gen. Microbiol., 49, 461.

Ito, T. AND NeILANDS, J. B. 1958. Products of "low iron fermentation" with Bacillus subtilis; isolation, characterization and synthesis of 2,3-dihydroxybenzoylglycine. $J$. Am. chem. Soc., 80, 4645.

L'Eplattenier, F., Murase, I. ANd Martell, A. E. 1967. New multidentate ligands. VI. Chelating tendencies of $\mathrm{N}, \mathrm{N}^{\prime}$-di (2-hydroxybenzyl) ethylenediamine- $\mathrm{N}, \mathrm{N}^{\prime}$-diacetic acid. J. Am. chem. Soc., 89, 837.

Lightbown, J. W. AND Sulitzeanu, D. 1957. The assay of penicillin in blood serum using Sarcina lutea. Bull. Wld Hlth Org., 17, 553.

MILES, A. A. 1951. The mouse pathogenicity and toxicity of Proteus vulgaris. J. gen. Microbiol., 5, 307.

Miles, A. A., MisRa, S. S. AND IRwin, J. O. 1938. The estimation of the bactericidal power of the blood. J. Hyg., Camb., 38, 732 .

Miles, E. M. AND Miles, A. A. 1951. The identity of Proteus hydrophilus Bergey et al. and Proteus melanovogenes Miles and Halnan, and their relation to the genus Aeromonas Kluyver and van Niel. J. gen. Microbiol., 5, 298.

NeILANDS, J. B. 1966. Naturally occurring non-porphyrin iron compounds. In Structure and bonding, Berlin, Heidelberg and New York, vol. 1, p. 59.

O'BriEN, I. G., Cox, G. B. AND GiBson, F. 1969. 2,3-dihydroxy-N-benzoylserine: chemical synthesis and comparison with the natural product. Biochem. biophys. Acta, 177, 321.

Peters, W. J. AND Warren, R. A. J. 1970. The mechanism of iron uptake in Bacillus subtilis. Can. J. Microbiol., 16, 1285.

Pollack, J. R., Ames, B. N. AND Neilands, J. B. 1970. Iron transport in Salmonella typhimurium; mutants blocked in the biosynthesis of enterobactin. J. Bact., 104, 635.

Pollack, J. R. AND NeIlands, J. B. 1970. Enterobactin, an iron transport compound from Salmonella typhimurium. Biochem. biophys. Res. Commun., 38, 989.

REICH, C. V. AND HANKs, J. H. 1964. Use of Arthrobacter terregens for bioassay of mycobactin. J. Bact., 87, 1317.

Rogers, H. J. 1973. Iron-binding catechols and virulence in Escherichia coli. Infect. Immun., 7, 445.

Smith, G. F., MCCURDY, W. H. JR AND DIEHL, H. 1952. The colorimetric determination of iron in raw and treated municipal water supplies by use of 4:7-diphenyl-1:10-phenanthroline. Analyst, 77, 418.

WALSH, B. L. AND WARREN, R. A. J. 1971. Iron uptake in Salmonella typhimurium. Can.J. Microbiol., 17, 213.

WANG, C. C. AND Newton, A. 1969. Iron transport in Escherichia coli; roles of energydependent uptake and 2,3-dihydroxybenzoylserine. J. Bact.. 98. 1142. 